\title{
Biosimilars in oncology: current and future perspectives
}

\section{Matti Aapro, MD}

Cancer represents a significant, and growing, burden on healthcare systems. This is driven, at least in part, by escalating cancer drug budgets. Loss of patent protection on biopharmaceuticals enables the development and production of similar biological medicines, or biosimilars. Biosimilars are currently available for use in oncology in the supportive care setting; the focus of biosimilar development is likely to switch to agents such as monoclonal antibodies. Available evidence indicates that biosimilars approved by regulatory authorities offer a safe and effective alternative to originator biological therapies. They also offer potentially significant cost savings to healthcare payers. The greater affordability of biosimilars may also result in clinical benefits, through earlier and wider appropriate therapy use and release of funding to be used elsewhere in clinical care. Greater adoption of biosimilars represents a key approach to reducing healthcare expenditure and improving patient access to important treatments.

\section{Keywords: Biosimilars, cost burden, oncology}

\section{The healthcare burden of cancer}

Cancer places a significant, and growing, burden on healthcare systems around the world. Improved therapies and changing demographics are conspiring to increase the already considerable drain on resources. On the one hand, population growth and ageing will increase the number of new cancer cases in the coming years [1]; on the other, advances in diagnosis and management will extend the length of treatment required for each patient [2]. Many novel treatments or supportive therapies for patients with cancer are biological agents. In fact, cancer is the major indication for six of the ten best-selling biological therapies [3]. The cost of new cancer drugs is rising every year [4], due in part to the higher research and development costs associated with biological rather than chemical medicines. In the US, the cost of cancer drugs rose four-fold between 1998 and 2008 [5], with more than $90 \%$ of the oncology therapies approved by the Food and Drug Administration (FDA) between 2005 and 2009 costing in excess of US $\$ 20,000$ for three months of treatment [6]. This growing cost burden is also being felt across Europe. The French budget for cancer therapies, for example, more than doubled from Euros 474 million to Euros 975 million between 2004 and 2008 [7]. These different factors form a complex situation that requires rapid action $[8,9]$.

Patent expiration on biopharmaceutical products provides pharmaceutical companies with an opportunity to develop and produce similar biological medicinal products, or biosimilars [10]. These agents may offer one way of controlling cancer drug expenditure while simultaneously expanding patient access to important treatments [11]. This paper will review current and future use of biosimilars in oncology, regulatory aspects of biosimilar approval, and current and future impact of these agents on cancer drug expenditure.

\section{Biosimilars in oncology: regulatory considerations}

Biological therapies are large, highly complex molecules derived from living cells or organisms. Traditional chemical medicines, by contrast, are usually simple molecules of low molecular weight, synthesised by chemical means. These differing complexities and methods of manufacture create an important difference between biosimilars and conventional generic drugs: while chemical generics can be fully characterised as identical to the originator product, biosimilars cannot. Biological therapies are inherently variable, creating unavoidable differences between even subsequent batches of the same product [12]. An expiring patent does not necessarily provide access to the precise manufacturing conditions used in producing the originator therapy, including, for example, the relevant cell line clone and growth medium. It therefore cannot be guaranteed that biosimilar products are identical to their reference product on a molecular level. In turn, this difference has important implications for the regulation and licensing of biosimilars. While conventional generic drugs require only a limited comparison and demonstration of identity to the reference product, biosimilars require far more rigorous testing. In general, there must be a thorough comparison of structural and functional characteristics of the biosimilar and originator therapy. Any identified microheterogeneities must then be assessed for their impact on safety and clinical performance.

In the EU, biosimilars are licensed through a thorough comparability exercise with the reference product, and clinical studies to ensure equivalence of efficacy and safety profiles. Guidelines produced by the European Medicines Agency (EMA) detail manufacturing process requirements, and the range of protein structure, isoform, aggregate, receptor binding and biological activity assays necessary to demonstrate biological equivalence [13]. EMA guidelines also outline the required clinical and non-clinical pharmacokinetic, pharmacodynamic and pharmacotoxological evaluations necessary to assess safety and efficacy before approval $[14,15]$. EMA guidelines have served as a starting point for development of licensing procedures in the US, where FDA released draft guidance for the regulatory review of biosimilars in early 2012 [16].

A number of biopharmaceutical agents will lose patent protection in Europe from 2014 onwards, and as a result more biosimilar medicines are likely to become available for use in oncology [17]. The focus of biosimilar development will shift from medicines used in the supportive care setting to agents that provide life-saving or lifeextending benefits such as monoclonal antibodies (mAbs). Following an extensive public consultation period, EMA has recently adopted its guideline on biosimilar monoclonal antibodies [18]. It recogn-

Author: Matti Aapro, MD, Institut Multidisciplinaire d'Oncologie, Clinique de Genolier, Case Postale (PO Box) 100, 3 Route du Muids, CH-1272 Genolier, Switzerland

Submitted: 2 April 2013; Revised: 24 May 2013; Accepted: 28 May 2013; Published online first: 10 June 2013 
ises the challenges that manufacturers may face in establishing similar clinical efficacy and safety of a biosimilar and reference $\mathrm{mAb}$ in the anticancer setting; preferred endpoints for confirming efficacy, such as progression-free, disease-free and overall survival, may not be feasible to establish biosimilarity as they may be influenced by factors, e.g. tumour burden, performance status, previous therapy, unrelated to differences between the biosimilar and reference $\mathrm{mAb}$. The guideline therefore acknowledges that surrogate endpoints such as overall response rate or change in tumour mass may be more appropriate.

\section{Biosimilars in oncology}

All biosimilar medicines currently approved by EMA are versions of recombinant human erythropoietin (epoetin), recombinant human granulocyte colony-stimulating factor (filgrastim) or recombinant human growth hormone. The biosimilar epoetins and filgrastims are used in oncology, for the treatment of chemotherapy-induced anaemia (biosimilar epoetins) and prevention of chemotherapy-induced neutropenia (biosimilar filgrastims). The availability of biosimilars has generated discussion among physicians about the possible concerns with prescribing these products [19].

The primary safety concern for biosimilars, as for all biological medicines, is immunogenicity. Most biological therapies elicit an immune response, in most cases with no clinical consequences. However, there are some biologicals for which immune responses have been linked to serious safety issues, notably the pure red-cell aplasia (PRCA) caused by cross-reacting neutralising antibodies against erythropoietin. Even small structural alterations may have an impact on immunogenicity, and analytical or animal data cannot always predict human immune responses. To mitigate this unavoidable risk, extensive non-clinical trial data demonstrating no increase in immunogenicity of the biosimilar compared with the reference product are required before a biosimilar can be licensed. In fact, the risk for detection of new and serious adverse effects after licensing is considered by some to be much lower for a biosimilar than for a biological containing a new or modified active substance [20]. Furthermore, the newer technologies used in manufacturing biosimilars mean that the products are generally of higher purity and quality, and more consistent potency, than their originator reference products [21]. Unfortunately, inadequately produced copies exist and can lead to major issues, as recently exemplified by numerous cases of PRCA in Thailand [22].

Ongoing pharmacovigilance is key to ensuring the safety of biopharmaceuticals. The pharmacovigilance programmes put in place by companies who market biosimilars are comparable in size and scope to those of originator companies, including a requirement to provide periodic safety update reports to the regulatory authorities. EMA requires a risk-management plan (RMP) to be implemented as a condition of marketing approval for all biopharmaceuticals, whether originator or biosimilar products. As an example, biosimilar epoetins have post-marketing studies as part of their RMPs to address potential safety issues such as PRCA, thromboembolic events and tumour treatment outcomes.

Patient exposure to biosimilars is increasing as adoption of these agents becomes more widespread. For example, the current (as of April 2013) estimated exposure to Binocrit (a biosimilar epoetin alpha) is over 216,000 patient-years, with more than 5,000 patients studied in clinical trials (data from the Sandoz periodic safety update report [PSUR] to EMA). As another example, the current estimated exposure to Zarzio (a biosimilar filgrastim) is 3.5 million patient-days (data from the Sandoz PSUR to EMA). It is reassuring that the adoption of biosimilars in general has so far not been associated with any unexpected safety concerns. A recent review of information gathered since biosimilar epoetins entered the market identified no difference in safety profiles between biosimilar and reference products, or between the alternative biosimilar formulations [23]. Similarly, a prospective randomised clinical study, conducted since licensing, has shown equivalence in pharmacokinetic and pharmacodynamics profiles, safety and clinical efficacy between originator and biosimilar epoetins [24].

\section{Cost savings associated with biosimilars:} current evidence and future possibilities Available evidence indicates that biosimilars offer a safe and effective alternative to originator biological therapies. They also offer potentially significant cost savings to healthcare authorities, which are desperately needed to control the current unsustainable levels of expenditure; sales of biopharmaceuticals amount to almost US\$70 billion in the US and Euros 60 billion in Europe [3, 25]. The development, manufacture and licensing requirements for biosimilars are considerably more rigorous than those for traditional generic drugs. The cost savings are therefore unlikely to be as large as sometimes observed for conventional generics, with savings in the region of $15-30 \%$ rather than $80 \%$ [26, 27]. A recent quantitative analysis of the European biosimilar market also concluded that biosimilars will result in smaller price reductions (and smaller market share) than conventional generic medicines [28]. Nevertheless, the potential cost savings are substantial-by some estimates, a 20\% reduction in the price of six off-patent biopharmaceuticals would save Euros 1.6 billion in Europe each year [29].

There is already evidence of the cost savings being made through adoption of biosimilars. For example, it is estimated that biosimilar epoetins saved Euros 60 million in Germany during their first year of availability - a figure that is projected to rise to Euros 8 billion by 2020 [30, 31]. Another analysis across seven European countries (France, Germany, Italy, Romania, Spain, The Netherlands and UK) calculated 2010 expenditure on epoetins in oncology to be US $\$ 1,117$ million [17]; assuming a 100\% switch to a biosimilar epoetin (at 2010 prices), US\$188 million would be saved per annum. A recent study has attempted to systematically forecast the savings that could be made by increasing use of biosimilar epoetin, filgrastim and monoclonal antibodies in eight European countriesFrance, Germany, Italy, Poland, Romania, Spain, Sweden and UK [31]. Analysis was based on prices between 2007 and 2010, and an estimate of future drug consumption through either theoretical requirements based on demographic and epidemiological estimates, or through estimated growth rates. A range of countryspecific scenarios were developed for the market and price progression of each biosimilar and its originator product. Assuming no biosimilars entered the market, estimated expenditure on the investigated biological therapies was Euros 229 billion between 2007 and 2020. By 2020, savings from biosimilar use ranged from Euros 11.8 to Euros 33.4 billion, depending on the model used. This represents $5.2 \%$ to $14.6 \%$ of total therapy expenditure. The bulk of these savings are expected to be made in France, Germany and UK-the 
countries that currently spend the most on biological drugs. Projections are likely to be most accurate for biosimilar epoetins, since these have been available in Europe for several years and therefore have known market trends. Here, savings of between Euros 9.4 and Euros 11.1 billion are estimated up to 2020 - a reduction of $21.5-25.5 \%$ from the baseline originator-only scenario. A model specifically designed to compare the comparative cost-efficiency of originator and biosimilar epoetins found that, for a patient undergoing six cycles of chemotherapy, the average cost of treatment was reduced from Euros 7,168 to Euros 4,643 through the use of biosimilar rather than originator epoetin alpha therapy [32].

\section{Biosimilars in oncology: how can they improve patient care}

The potential cost savings through adoption of biosimilar medicines are important to society in general, but it is also important to consider how adoption of these agents might improve patient care. One possibility is that improved affordability may increase patient access to the most appropriate therapies at an earlier time during their illness. In a non-interventional study conducted in a community oncology centre, switching from originator to biosimilar filgrastim was accompanied by a trend towards increased use of filgrastim as primary prophylaxis [33], which may reflect greater willingness to use biosimilar filgrastim earlier given its lower cost. Another possibility is that cost savings made by using biosimilar medicines in the supportive care setting could be reinvested to expand patient access to currently available life-extending or life-saving treatments. As an example, the saving of US $\$ 188$ million generated by switching to biosimilar epoetin (described previously) would support rituximab therapy for an additional 9,000 patients [17]. Finally, with upwards of 500 oncology biologicals currently in development pipelines, a third possibility is that greater uptake of existing and future biosimilars will permit funding of these new biological cancer treatments.

\section{Conclusion}

In the current climate of growing financial constraints on healthcare systems and impending patent expiry on major biological therapies used in oncology, biosimilars offer an important opportunity to provide high quality and clinically effective medications at reduced cost. Their greater affordability may, in fact, result in clinical benefits through earlier and wider therapy use, and release of funding to be used elsewhere in clinical care. With the appropriate regulation and monitoring in place, increasing adoption of biosimilars represents a key approach in reducing healthcare budgets and improving patient access to important therapies.

\section{Acknowledgements}

Medical writing assistance in the preparation of this paper was provided by Dr Tony Reardon of Spirit Medical Communications Ltd and funded by Sandoz International GmbH.

Competing interests: Dr Matti Aapro has acted as an advisor to, and received speaker fees from, Sandoz.

Provenance and peer review: Not commissioned; externally peer reviewed.

\section{References}

1. Uyl-de Groot CA, de Groot S, Steenhoek A. The economics of improved cancer survival rates: better outcomes, higher costs. Expert Rev Pharmacoecon Outcomes Res. 2010;10(3):283-92.

2. Albreht T, McKee M, Alexe DM, Coleman MP, Martin-Moreno JM. Making progress against cancer in Europe in 2008. Eur J Cancer. 2008;44(10):1451-6.

3. Hirsch BR, Lyman GH. Biosimilars: are they ready for primetime in the United States? J Natl Compr Canc Netw. 2011;9(8):934-42.

4. Bach PB. Limits on Medicare's ability to control rising spending on cancer drugs. N Engl J Med. 2009;360(6):626-33

5. Mulcahy N. Time to consider cost in evaluating cancer drugs in United States? Medscape Medical News. 2009 [cited 2013 May 24]. Available from: http://www.medscape.com/viewarticle/705689

6. Fojo T, Grady C. How much is life worth: cetuximab, non-small cell lung cancer, and the $\$ 440$ billion question. J Natl Cancer Inst. 2009;101(15):1044-8.

7. Perrin S. Therapeutic decision making in oncology. Hosp Pharm Europe. 2010;52:36-7.

8. Sullivan R, Peppercorn J, Sikora K, Zalcberg J, Meropol NJ, Amir E, et al. Delivering affordable cancer care in high-income countries. Lancet Oncol. 2011;12(10):933-80.

9. Cavalli F. An appeal to world leaders: stop cancer now. Lancet. 2013;381(9865):425-6.

10. Dranitsaris G, Amir E, Dorward K. Biosimilars of biological drug therapies: regulatory, clinical and commercial considerations. Drugs. 2011;71(12):1527-36.

11. Aapro M, Cornes P. Biosimilars in oncology: emerging and future benefits. Eur J Oncol Pharm. 2012;6 (2):27-9

12. Weise M, Bielsky MC, De Smet K, Ehmann F, Ekman N, Narayanan G, et al. Biosimilars-why terminology matters. Nat Biotechnol. 2011;29(8):690-3.
13. European Medicines Agency. Guideline on similar biological medicinal products containting biotechnology-derived proteins as active substance: quality issues [homepage on the Internet]. 2006a [cited 2013 May 24]. Available from: http://www. ema.europa.eu/docs/en_GB/document_library/ Scientific_guideline/2009/09/WC500003953.pdf

14. European Medicines Agency. Guideline on similar biological medicinal products containing biotechnology-derived proteins as active substance: non-clinical and clinical issues [homepage on the Internet]. 2006b [cited 2013 May 24]. Available from: http://www.ema.europa.eu/docs/en_GB/ document_library/Scientific_guideline/2009/09/ WC500003920.pdf

15. European Medicines Agency. Guideline on immunogenicity assessment of biotechnologyderived therapeutic proteins [homepage on the Internet]. 2007 [cited 2013 May 24]. Available from: http://www.ema.europa.eu/docs/en_GB/ document_library/Scientific_guideline/2009/09/ WC500003947.pdf

16. US Food and Drug Administration. Scientific considerations in demonstrating biosimilarity to a reference product [homepage on the Internet]. Draft guidance. 2012 [cited 2013 May 24]. Available from: http://www.fda.gov/downloads/ Drugs/GuidanceComplianceRegulatoryInformatio n/Guidances/UCM291128.pdf

17. Grande E, Carrato A. Biosimilars: what they are and their use in oncology. Cancer Chemother Rev. 2011;6(3):23-30.

18. European Medicines Agency. Guideline on similar biological medicinal products containing monoclonal antibodies - non-clinical and clinical issues [homepage on the Internet]. 2012 [cited 2013 May 24]. Available from: http://www.ema.europa.eu/ docs/en_GB/document_library/Scientific_guideline/2012/06/WC500128686.pdf

19. Aapro M. What do prescribers think of biosimilars? Target Oncol. 2012;7 Suppl 1:S51-5

20. Weise M, Bielsky MC, De Smet K, Ehmann F, Ekman N, Giezen TJ, et al. Biosimilars: what clinicians should know. Blood. 2012;120(26):5111-7.

21. Brinks V, Hawe A, Basmeleh AH, Joachin-Rodriguez L, Haselberg R, Somsen GW, et al. Quality of original and biosimilar epoetin products. Pharm Res. 2011;28(2):386-93.

22. Praditpornsilpa K, Tiranathanagul K, Kupatawintu P, Jootar S, Intragumtornchai T, Tungsanga K, et al. Biosimilar recombinant human erythropoietin induces the production of neutralizing antibodies. Kidney Int. 2011;80(1):88-92.

23. Abraham I, MacDonald K. Clinical safety of biosimilar recombinant human erythropoietins. Expert Opin Drug Saf. 2012;11(5):819-40.

24. Lissy M, Ode M, Roth K. Comparison of the pharmacokinetic and pharmacodynamic profiles of one US-marketed and two European-marketed epoetin alfas: a randomized prospective study. Drugs R D. 2011;11(1):61-75.

References $25-33$ can be found on page 96 . 


\section{Biosimilars in oncology: current and future perspectives \\ References (please see the full manuscript on page 91-93)}

25. Covic A, Cannata-Andia J, Cancarini G, et al. Biosimilars and biopharmaceuticals: what the nephrologist needs to know - a position paper by the ERA-EDTA Council. Nephrol Dial Transplant. 2008;23(12):3731-7.

26. Blackstone EA, Fuhr JP Jr. Biopharmaceuticals: the economic equation. Biotechnol Healthc. 2007;4(6):41-5.

27. Simoens S. Biosimilar medicines and costeffectiveness. Clinicoecon Outcomes Res. 2011;3: 29-36.

28. Olry de Labry A, Giménez E, Lindner L, Garcia L, Espin J, Rovira J. Biosimilars in the European market. Generics and Biosimilars Initiative Journal (GaBI Journal). 2013;2(1):30-5. doi:10.5639/gabij.2013.0201.012

29. European Generic medicines Association. The future of pharmaceuticals: generic medicines enhancing pharmaceutical competition and ensuring healthcare sustainability issues [homepage on the Internet]. 2007 [cited 2013 May 24]. Available from: http://198.170.119.137/doc/ ega_FuturePharmaceuticals.pdf

30. IGES Institute, The competitive role of biosimilars in the German SHI market for pharmaceuticals, 2010.

31. Höer AdM, C, Häussler B, Haustein R. Saving money in the European healthcare systems with biosimilars. Generics and Biosimilars Initiative Journal (GaBI Journal). 2012;1(3-4):
120-6. doi:10.5639/gabij.2012.0103-4.036

32. Aapro M, Cornes P, Sun D, Abraham I. Comparative cost efficiency across the European G5 countries of originators and a biosimilar erythropoiesis-stimulating agent to manage chemotherapy-induced anemia in patients with cancer. Ther Adv Med Oncol. 2012;4(3):95-105.

33. Verpoort K, Mohler TM. A non-interventional study of biosimilargranulocyte colony-stimulating factor as prophylaxis for chemotherapy-induced neutropenia in a community oncology centre. Ther Adv Med Oncol. 2012;4(6):289-93.

DOI: 10.5639 /gabij.2013.0202.023

Copyright (C 2013 Pro Pharma Communications International 